3-2021

\title{
Architecture, Social Norms, and Their Economic Consequences in Japan
}

Koichi Kume

Faculty of Economics, Toyo University

Follow this and additional works at: https://gensoken.toyo.ac.jp/japanese-society-and-culture

Part of the Behavioral Economics Commons, Labor Economics Commons, and the Sociology of Culture Commons

\section{Recommended Citation}

Kume, Koichi (2021) "Architecture, Social Norms, and Their Economic Consequences in Japan," Japanese Society and Culture: Vol. 3 , Article 11.

DOI: 10.52882/2434-1738-0311

Available at: https://gensoken.toyo.ac.jp/japanese-society-and-culture/vol3/iss1/11

This Research Note is brought to you for free and open access by Institute of Social Sciences. It has been accepted for inclusion in Japanese Society and Culture by an authorized editor of Institute of Social Sciences. 


\title{
Architecture, Social Norms, and Their Economic Consequences in Japan*
}

\author{
Koichi Kume ${ }^{* *}$
}

\begin{abstract}
Law and market mechanisms presuppose that people are rational. With the diversification of lifestyles and values, however, there is a limit to appealing only to economic rationality to implement social policies. In this study we focus on architecture as a policy instrument that does not presuppose people's rationality and empirically analyze the effect on economic consequences in Japan. Specifically, we examine the relationship between bank transfers and poverty reduction, and that between statues (Sontoku Ninomiya, Jizo) and labor norms. The results suggest that the use of architecture in policy can improve policy effectiveness regardless of people's irrationarity and heterogeneous preferences.
\end{abstract}

\section{Keywords: Architecture, Social Norms, Behavioral Economics}

\section{Four modalities of policy measures}

In general, a means for achieving a certain purpose is called a policy. According to Lessig $(1998,2008)$, policy measures have four modalities. One is the law. Those who violate the rules will be punished by public authority, which includes criminal penalties and police enforcement. The second is norms. People preach desirability based on community values and implicitly order others to obey common values. The third is the market, which changes people's behavior by appealing to their economic incentives by manipulating the prices of substitutable goods and services. Finally, architecture is the physically created environment. For example, a bench "armrest" that physically prevents a person from lying down 1 even if they want to. "Any aspect of the choice architecture that alters people's behavior in a predictable way without forbidding any options or significantly changing their economic incentives" is called a nudge (Thaler and Sunstein 2003, 2009).

Traditional economics has emphasized market function and presupposed the economic rationality of people. However, this is not enough to increase the welfare of irrational people, and it is becoming necessary to deal with the occurrence of negative externality due to irrational behavior ${ }^{2}$. By contrast,

\footnotetext{
※ This paper is a revised version of part of Kume (2018) in English, which added figures, explanation of Japanese technical terms and details of the survey design.

※ Associate professor, Faculty of Economics, Toyo University

1 As summarized by Ohya (2012), regulation by architecture has several characteristics. The law imposes ex post sanctions in the form of punishment, but architecture pre-regulates and unknowingly limits the possibility of action. Architecture is also definitely effective for those with strong wills and special preferences who do not reasonably respond to punishment or financial rewards.

2 For example, a third party will bear the cost by providing medical services for the health damage caused by the person's unhealthy life, and by providing livelihood relief even if he / she falls into multiple debt as a result of a wasted life.
} 
behavioral economics, which assumes irrationality and makes use of it, proposes policies using architecture and norms. In other words, it is time for policymakers to improve the effectiveness of policy instruments by considering the relationship between the heterogeneity of people's preferences, such as risk and time preference, and the economic consequences. In the following sections, we provide concrete examples in Japan that apply architecture and norms as policy instruments, and we discuss how to expand the possibilities of these types of policies.

\section{Example 1: Poverty reduction}

What can we do for the poor? To consider this issue, it is necessary to understand the relationship between people's preferences, behavioral characteristics, and the conditions of poverty. Kume et al. (2013) examined relative deprivation ${ }^{3}$, social exclusion ${ }^{4}$, economic preferences, and behavioral characteristics of day labor dispatched workers, who are called the working poor ${ }^{5,6}$. Poverty conditions include lack of basic needs, lack of social relations, exclusion from institutional services, and high subjective poverty.

Regarding economic preferences, we focus on risk preferences and time preferences. Both are important parameters that influence human decision-making under uncertainty. Risk preference presents as attitude toward risks, and we created a four-level risk avoidance scale from virtual questions? ${ }^{7}$. We ask the question "When did you work on your summer vacation homework?" to measure time preference 8 . We also define hyperbolic discounting ${ }^{9}$ as the time discount rate in the near future being higher than the time discount rate in the distant future. Homework during the summer vacation is a proxy for procrastination of painful duty, which people with a high preference for the present tend to postpone.

Figure 1 shows the relationship among risk preference, poverty, and social exclusion indicators. The vertical axis represents the social exclusion rate. It can be seen that risk lovers have a high social exclusion rate (Figure 1-left). Although there are some aspects of not getting high returns without taking risks, this case shows that risk lovers are prone to more serious poverty.

Next, looking at the relationship among time preference, poverty, and social exclusion indicators on the right side of Figure 1, we find that those who postpone their summer vacation homework have a high social exclusion rate. Myopia or postponement of painful duty makes poverty more severe. In addition, although figures are omitted here, those who tend to have hyperbolic discounting were in a more difficult situation in terms of basic needs and subjective poverty 10 .

\footnotetext{
3 Relative deprivation refers to the level of deprivation of goods, services, and institutional services that should be naturally received in society.

4 Social exclusion means that people are isolated and excluded from social relations (Townsend 1979).

5 A day labor dispatched worker is a dispatched worker whose labor contract period is 30 days or less. Because of the revision of the Worker Dispatching Law, it was banned in principle from October 1, 2012.

6 Kume et al. (2013) use data from the internet survey called "RIETI Dispatch Worker Survey" conducted by the Research Institute of Economy, Trade and Industry in January 2009. This survey randomly selects those who are not in stable jobs from registered monitors owned by Internet research firm. The number of valid respondents is 2157 , and the valid response rate is $71.9 \%$.

7 To measure the degree of risk avoidance, we used a choice problem of a method of paying compensation for work; A. a $50 \%$ chance that the monthly income will be doubled or decreased by $30 \%$, or B. a $5 \%$ increase in the current monthly income is confirmed. We asked four questions about a method of paying compensation and regard those that chose a reward system with low fluctuation risk as risk-avoidant.

8 It is important not only whether you intended to do your homework, but also whether you actually did it. See O'Donoghue and Rabin (1999) for commitments.

9 "Hyperbolic discount" is a dummy variable where the interest received when a 10,000 yen payment received 2 days later is extended after 9 days is higher than that received when 10,000 yen received 90 days later is extended 97 days later.

10 Basic needs refer to the inability to purchase food, clothing, medical and medical (dental) goods and services for financial reasons. Lack of social relations (whether or not they have conversations with people, whether it
} 
Figure 1. Poverty situation by risk preference (left) and time preference (right)
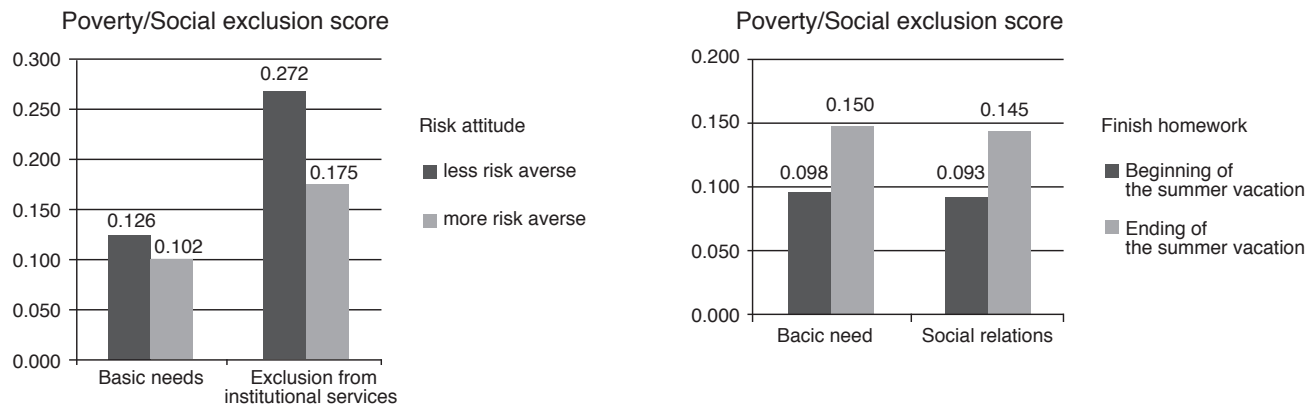

Source: Created graphs from Kume et al. (2013) Figure 3

Regarding behavioral characteristics, let us focus on the method and frequency of salary payments (Figure 2). The social exclusion rate is lower when a bank transfer is the salary payment method than when it is hand-delivery, and the social exclusion rate for monthly payment is lower than that of weekly or daily payments. The results imply that the degree of social exclusion clearly differs depending on how the reward is paid, whether or not the person intends to isolate themselves socially.

Figure 2 Behavioral characteristics and poverty situation
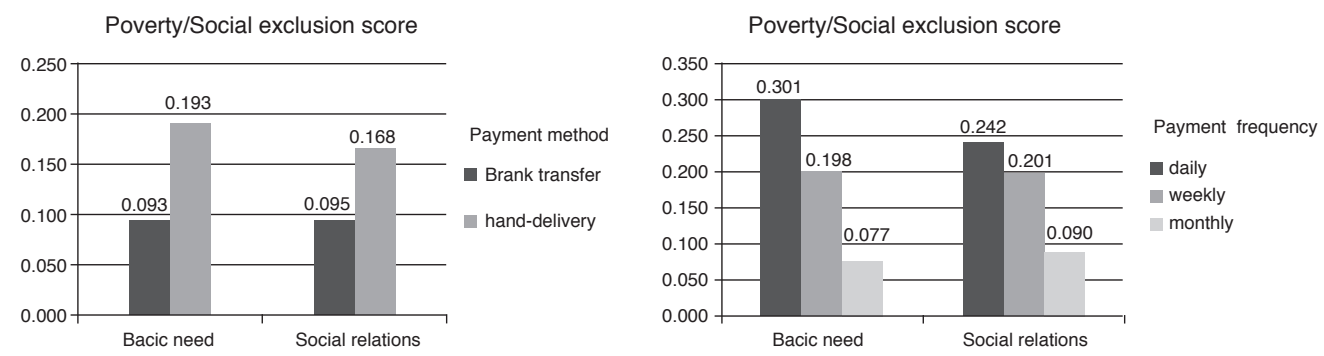

Source: Created graphs from Kume et al. (2013) Figure 3

To transcend poverty, poor people need to save money to prepare for their lives and for unexpected future risks. The preferences and behavioral characteristics of poor people, however, show that they are risk-loving, myopic, prefer hand-delivered payment, and often receive cash benefits, which makes it difficult for them to save money.

What kind of policy can be considered to help poor people? Following the four modalities suggested by Lessig (2002), governments might enact a bill to force poor people to save some percentage of their salary (law), convince them that saving is a virtue (norm), and set transaction fees and deposit interest

is economically possible to meet friends, family, and relatives, and whether or not it is economically possible to attend relatives' ceremonial occasions). Exclusion from the system is defined by the presence or absence of public employment insurance, public medical insurance, and public pension. Subjective poverty is measured by the subjective standard of living and the ability to save money. 
rates that give preferential treatment to poor people (market). It is also a good idea to set up the monthly savings payment by bank transfer as the default (architecture). People in poverty are myopic ${ }^{11}$ and may use up their money quickly when they receive cash or hand-delivered rewards. Although delaying the payment period and implementing bank transfers might be inconvenient, they may enable the promotion of unintended savings and open up the possibility of poverty alleviation.

\section{Example 2: Labor norm}

It is often discussed whether Japanese are diligent? ${ }^{12}$ Diligence is encouraged not only because it is an expression of an individual's religious spirit and moral conduct, but also because it can contribute to the accumulation of social wealth as a whole13. Before World War II in Japan, this "diligence" thought was incorporated into education to foster people who voluntarily devoted themselves to the nation. As an example, statues of Sontoku Ninomiya (childhood name: Kinjiro, Figure 3 left), a famous agricultural politician and thinker in the Edo period, were built in elementary schools all over Japan ${ }^{14}$. The existence of the statue played a role in promoting social ties and integration centered on agricultural policy, while sending a normative message of diligence to children. 15

Is this message valid in modern Japan? Kume (2014) empirically analyzes the relationship between statues and social norms ${ }^{16}$. On the left side of Figure 4, the relationships between the presence or absence of the statue of Sontoku Ninomiya ("Was there a statue of Kinjiro Ninomiya in the elementary school or junior high school you attended?") and the normative awareness of labor ("It is embarrassing to receive money without working") are shown by generation ${ }^{17}$. On average, the burnt (yakeato) generation scores the highest normative consciousness, and the ice age (hyogaki) generation has the lowest norm. However, in most generations, it can be seen that those who recognize that their schools did have a statue of Sontoku Ninomiya have a higher sense of norm than those who "did not have" or "did not know" the statue.

11 Why do we become myopic? Mullainathan and Shafir (2014) point out a vicious cycle of deficiency. In other words, a poor state leads to a decrease in processing capacity which leads to greater poverty.

12 Yamamoto (1984) regards work and savings as a Japanese virtue, religious training, and part of Buddhism, but Takeda (2008) analyzed that diligence in Japan is a discipline and has been established in the process of organizing the factory labor force in modernization.

13 Weber (1885) states that the spirit of Christian abstinence based on vocational philosophy gave rise to a rational lifestyle that supported capitalism. However, in recent years, Cantoni (2015) has demonstrated that Protestantism did not contribute to economic growth and the debate is ongoing.

14 Demolished when the school buildings were rebuilt in 1980s. In addition, Inoue (1998) pointed out that the statue of Kinjiro as a symbol of the hard worker has been replaced by statues that reflect "warm touch" or "hope" to encourage a school life that focused on playing.

15 Note that Inoue (1998) pointed out the statue of Kinjiro Ninomiya was promoted not by the goverment but by copperware and stone vendors.

16 Kume (2014) analyzes data of the "Survey on Young People"s Life and Households" conducted by the Institute for Research on Household Economics. This internet survey was conducted in March 2013. The number of response requests was 9,910 , and the number of valid respondents was 3,570 (response rate $36.0 \%$ ).

17 The definition of each generation is as follows; 1) The burnt generation (Yakeato sedai) was born between 1935 and 1946 and were children during WW2. 2) The baby boomer generation (Dankai sedai) was born between 1947 and 1949. 3) The apathetic generation (Shirake sedai) was born between 1950 and 1964 and being a later generation of student activism, lacked political interest. 4) The bubble generation (Baburu sedai) was born between 1965 and 1974 and entered the workforce in the 1980s and the early 1990s at the height of Japan's postwar economic miracle. 5) The ice age generation (Hyogaki sedai) was born between 1974 and 1982 and entered the workforce during the "lost decade" and experienced difficulty in finding full-time employment. 6) The relaxed education system generation (Yutori sedai) was born between 1987 and 2004. They were educated under the revised educational system with reduced hours and curriculum content and are often challenged by scholastic ability and competitiveness. As an example of an analysis of social norms by generation, Tashiro and Lo (2020) found an inverse relationship between adherence to social norms and labor force participation among Japanese women, and the effect of obedience to social norms on wages varies by birth cohort. 
Figure 3 Statues (left: Sontoku Ninomiya, right: Jizo)
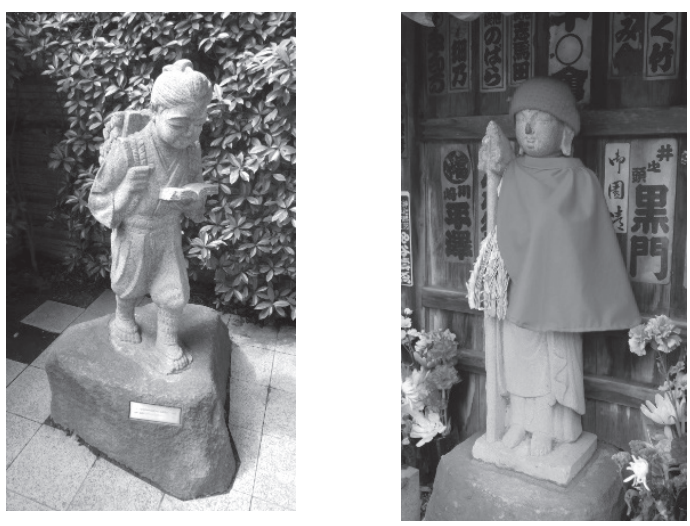

Source: Photographed by the author

As another example, let us consider Jizo. Jizo is a Bodhisattva of the Buddhist religion, and is often placed outdoors on the outskirts of villages, crossroads, and mountain passes. For children, it means an entrance to another world or a warning of danger. In addition, the famous Japanese classic story, "Kasa Jizo,"18 tells us that those who do the right thing will be saved. In real life, it is presumed that experiencing the consciousness of "Jizo looking" promotes the internalization of the consciousness of doing the right thing ${ }^{19}$.

On the right side of Figure 4, the relationship between two sentences is shown: a normative consciousness that "work is necessary to make full use of talent" and the presence of a Jizo statue in the neighborhood or on the roadside going to and from school in childhood. In particular, it can be seen that those who had Jizo have a higher awareness of labor norms in the burnt (yakeato), baby boomer, and yutori generations ${ }^{20}$.

Figure 4 Labor norm awareness and architecture (left: Sontoku Ninomiya statue, right: Jizo)
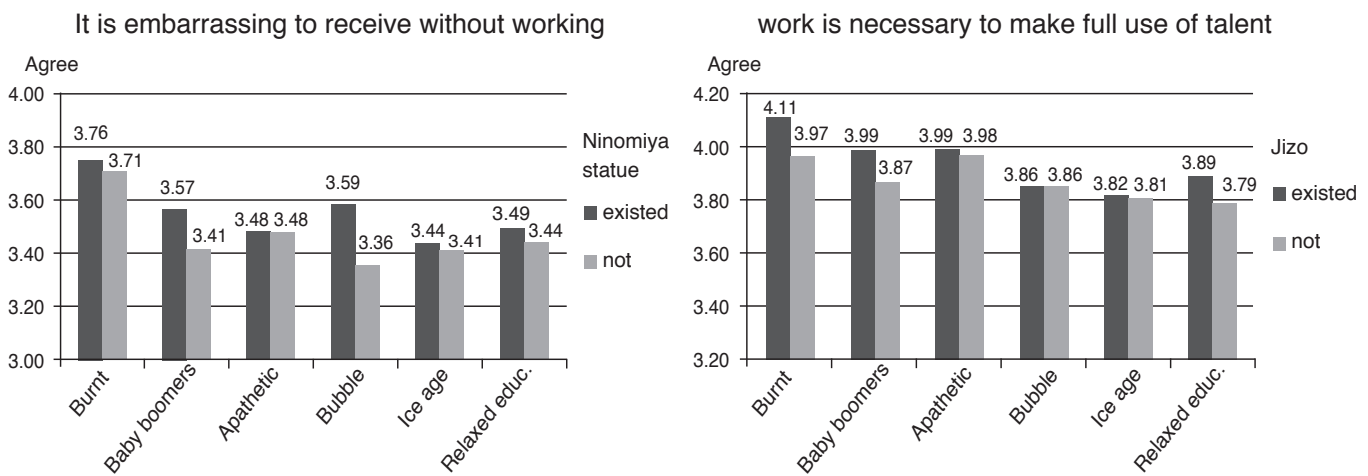

Source: Kume (2014) Figure 3, 5

\footnotetext{
18 Kasa (Straw Hats) jizo is a typical story that unexpected good luck is brought as a reward to a selfless good deed that has given kindness. Specifically, a poor but pure-hearted old couple puts Kasa on the roadside stone Jizo and receives gratitude.

19 See Bateson et al. (2006) and Oda et al. (2011) for the internalization of normative consciousness by being seen.

20 Ito et al. (2020) show that people who have shrines, temples, and Jizo in their neighborhood generally tend to trust people and be altruistic.
} 
These results suggest that the architecture of Sontoku Ninomiya and Jizo contributed to the internalization of the normative awareness of labor ${ }^{21}$. What kind of economic outcomes will this normative awareness bring? According to Kume (2014), people with a high awareness of labor norms have high job satisfaction and work longer hours. As the architecture intends, it drives people to work, eliciting greater satisfaction and motivation than otherwise.

\section{Conclusion}

In this study, we focused on architecture and norms as policy instruments that do not necessarily presuppose the rationality of people, and discussed application examples for poverty reduction and fostering labor norms in Japan. The characteristic of these instruments is that they actively use the heterogeneity of preferences, as seen in people's cognitive patterns and behavioral habits. To deal with modern economic environmental changes, faster and more effective policy instruments are needed. The costs of architecture and norms for procedures and transactions are relatively lower than those of laws and markets that require institutional reform, and there is no reason not to take advantage of them.

To implement these policies, it is necessary to clarify the ethical validity and procedural legitimacy of policy makers' decisions to obtain people's approval. Considering that we are faced with many social and economic issues that need to be solved, architecture and norms are attractiave policy measures and how we can implement in society depends on our experimental spirit.

\section{References}

Bateson, Melissa, Daniel Nettle and Gilbert Roberts 2006 "Cues of being watched enhance cooperation in a real-world setting,” Biology Letters, 2(3), pp. 412-414.

Cantoni, Davide 2015 "The Economic Effects of the Protestant Reformation: Testing the Weber Hypothesis in the German Lands," Journal of the European Economic Association, 13(4) pp. 561-598.

Inoue, Shoichi (1998) Kinro to bengaku no zuzogaku: Ninomiya Kinjiro zo no seisui o megutte [Picture of deligence and study: Rise and fall of the statue of Ninomiya Kinjiro] Nihonjin no rodo to asobi, rekishi to genjo, 16, pp. 133-140.

Ito, Takahiro, Kohei Kubota and Fumio Ohtake (2000) "Long-term consequences of the hidden curriculum on social preferences," The Japanese Economic Review.

Kume, Koichi (2014) Rodo ni kansuru kihan ishiki no keisei to sono eikyo [Formation of labor norm and the effects on economic outcomes] Japanese journal of research on household economics, 102 号 pp. 44-56.

Kume, Koichi (2018) Koudou keizaigaku ga seisaku shudan wo yutakani suru -architecuture to kihan wo seisaku ni ikasu [Behavioral Economics Enriches Policy Means-Using Architecture and Norms in Policy] Nextcom 35, pp. 14-23.

Kume. Koichi, Fumio Ohtake, Kotaro Tsuru and Hiroko Okudaira (2013) Hiseki roudousha ni okeru shakaitekihaijo no jittai to sono youin [Measuring Social Exclusion of Non Regular Workers in Japan], The Japanese journal of labour studies, 634, pp. 100-115. The Japan Institute for Labour Policy and Training.

21 Kume et al. (2015) clarified that childhood life experiences affect the formation of non-cognitive abilities and normative consciousness which are transmitted to various economic outcomes in their adulthood. 
Kume, Koichi, Chie Hanaoka, Noriko Mizutani, Fumio Ohtake and Naoko Okuyama (2015) Personality tokusei no keiseiyouin - katei, gakkou, shokuba no keiken kara [Factors forming personality traits-from home, school, and work experience] Journal of Behavioral Economics and Finance 7, pp.50-54.

Lessig, Lawrence (1998) “The New Chicago School,” Journal of Legal Studies Vol. XXVII (2) pp. 661-691.

Lessig, Lawrence (2000) Code: And Other Laws of Cyberspace, Basic Books

Mullainathan, Sendhil, and Eldar Shafir (2014) Scarcity: Why Having Too Little Means So Much, Times Books

Oda, Ryo, Yuki Niwa, Atsushi Honma and Kai Hiraishi (2011) "An eye-like painting enhances the expectation of a good reputation,” Evolution and Human Behavior, 32(3), pp. 166-171.

O’Donoghue, Ted, and Matthew Rabin (1999) “Doing It Now or Later," American Economic Review, 89(1): pp. 103-124.

Ohya, Takehiro (2012) On architecture and policy, Ministry of Internal Affairs and Communications, Study group on how to ensure the effectiveness of administration in response to the progress of decentralization, September 26, 2012.

Takeda, Haruhito (2008) Nihonjin no Keizai Kannen Rekishi ni miru Itan to fuhen [Economic idea of Japanese-Heresy and universal in history] Tokyo, Iwanami shoten

Tashiro, Sanae and Chu-Ping Lo (2020) "When Social Norms Influence the Employment of Women: The Case of Japan,” Eastern Econ Journal 46, pp. 460-482.

Thaler Richard H. and Cass R. Sunstein (2003) "Libertarian Paternalism Is Not an Oxymoron” University of Chicago Public Law \& Legal Theory Working Paper No. 43.

Thaler Richard H. and Cass R. Sunstein (2009) Nudge: Improving Decisions About Health, Wealth, and Happiness Penguin Books

Townsend, Peter (1979) Poverty in the United Kingdom, Allen Lane and Penguin Books

Weber, Max (1905) Die protestantische Ethik und der Geist des Kapitalismus. The Protestant Ethic and the Spirit of Capitalism, Tokyo, Iwanami shoten

Yamamoto, Shichihei (1984) Kinben no Tetsugaku - Nihonjin wo ugokasu genri [Philosophy of Diligence The principle to motivate Japanese] Tokyo, PHP 